\title{
Membrane-Integrated Glass Capillary Device for Preparing Small- Sized Water-in-Oil-in-Water Emulsion Droplets
}

\author{
Kazuki Akamatsu, ${ }^{*}{ }^{\dagger}, \ddagger$ Shosuke Kanasugi, ${ }^{\dagger}$ Shin-ichi Nakao, ${ }^{\dagger}$ and David A. Weitz ${ }^{\ddagger}$, \\ ${ }^{\dagger}$ Department of Environmental Chemistry and Chemical Engineering, School of Advanced Engineering, Kogakuin University, 2665-1 \\ Nakano-machi, Hachioji-shi, Tokyo 192-0015, Japan \\ ${ }^{\ddagger}$ School of Engineering and Applied Sciences, and ${ }^{\S}$ Department of Physics, Harvard University, Cambridge, Massachusetts 02138 , \\ United States
}

\section{Supporting Information}

ABSTRACT: In this study, a membrane-integrated glass capillary device for preparing small-sized water-in-oil-in-water (W/O/W) emulsion droplets is demonstrated. The concept of integrating microfluidics to prepare precise structure-controlled double emulsion droplets with the membrane emulsification technique provides a simple method for preparing small-sized and structure-controlled double emulsion droplets. The most important feature of the integrated device is the ability to decrease droplet size when the emulsion droplets generated at the capillary pass through the membrane. At the same time, most of the oil shell layer is stripped away and the resultant double emulsion droplets have thin shells. It is also demonstrated that the sizes of the resultant double emulsion droplets are greatly affected by both the double emulsion droplet flux through membranes and membrane pore size; when the flux is increased and membrane pore size is decreased, the generated W/ $\mathrm{O} / \mathrm{W}$ emulsion droplets are smaller than the original. In situ observation of the permeation behavior of the W/O/W emulsion droplets through membranes using a high-speed camera demonstrates (1) the stripping of the middle oil phase, (2) the division of the double emulsion droplets to generate two or more droplets with smaller size, and (3) the collapse of the double emulsion droplets. The first phenomenon results in a thinner oil shell, and the second division phenomenon produces double emulsion droplets that are smaller than the original.

\section{INTRODUCTION}

A double emulsion is an interesting system comprising emulsion droplets in which smaller droplets are contained. Because of the unique and highly hierarchized structure, a variety of applications, such as encapsulation and controlled chemical release, have been demonstrated. ${ }^{1,2}$ Another potential application for double emulsion droplets is to use them as templates for preparing functional particles, such as hollow microcapsules, ${ }^{3,4}$ liposomes, ${ }^{5-7}$ colloidosomes, ${ }^{8,9}$ and polymersomes. ${ }^{10,11}$

However, it is rather difficult to prepare a double emulsion because, in general, two emulsification steps are required to form drop-in-drop structures. ${ }^{12-14}$ The microfluidic approach is one of the most feasible ways to prepare a double emulsion. Nishisako et al. developed microfluidic devices with two Tjunctions. ${ }^{15}$ At the first T-junction, a primary single emulsion is prepared, and at the second the primary single emulsion droplets are encapsulated by the outermost continuous phase. $\mathrm{Chu}$ et al. developed microfluidic devices that employ two sequential coflow emulsion generators. ${ }^{16}$ The design of these types of devices is flexible, and enables stepwise emulsification to prepare precise structure-controlled double emulsions. Utada et al. first developed a glass capillary device which enables a

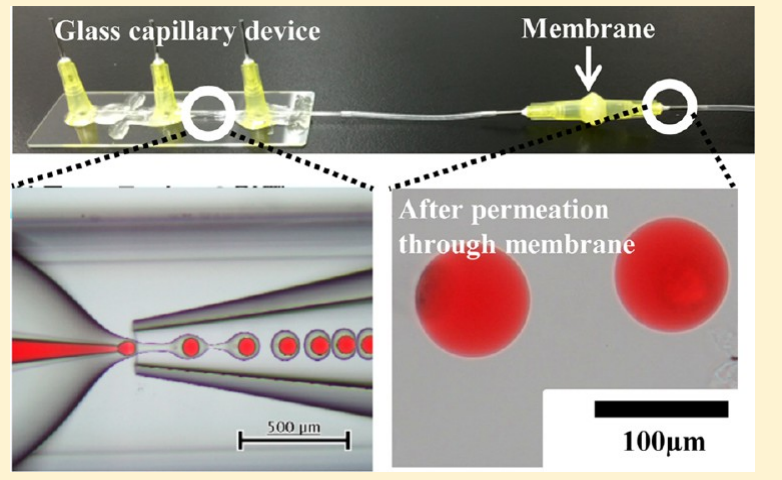


under pressure. ${ }^{22,23}$ The division of larger emulsion droplets occurred repeatedly inside the pores during permeation, and accordingly size-controlled emulsion droplets were obtained in the permeate. The sizes of the resultant emulsion droplets largely depend on the pore sizes of the membranes used. The monodispersity of the emulsion droplets prepared by premix emulsification is somewhat worse than that achieved by direct emulsification; however, a very high production rate is observed with the premix emulsification method. There have been some reports on the preparation of functional particles using the premix emulsification technique. ${ }^{24-26}$ However, almost all of these studies dealt with single emulsions, and there has been no study on the permeation of precise structure-controlled double emulsion droplets, such as those generated with a microfluidic approach. In addition, demulsification reportedly occurs by permeation through membranes in certain cases. ${ }^{27}$

Here, we demonstrate a novel microfluidic device that integrates the glass capillary device with a porous glass membrane to prepare double emulsion droplets with diameters less than $100 \mu \mathrm{m}$. A Shirasu porous glass (SPG) membrane is employed because a number of papers have reported its use for successful emulsification. The pore diameter of the SPG membrane is determined by preparation conditions, and those with a pore size of less than $50 \mu \mathrm{m}$ are commercially available. Thus, the sizes of the double emulsion droplets passing through the SPG membrane are expected to be determined mainly by the pore size of the SPG membrane and permeation flux, and will be less than $100 \mu \mathrm{m}$ under suitable conditions. We demonstrate the permeation properties of water-in-oil-in-water $(\mathrm{W} / \mathrm{O} / \mathrm{W})$ type double emulsion droplets, which are generated with a glass capillary device, through SPG membranes of different pore size under different flux conditions. We also develop an integrated device of a glass capillary device with an SPG membrane, and investigate permeation dynamics by direct observation of the permeation behavior using a high-speed camera.

\section{EXPERIMENTAL SECTION}

Materials. Glucose, kerosene, and sodium dodecyl sulfate (SDS) were purchased from Wako Pure Chemical Industries Ltd. (Japan). Allura Red, poly(vinyl alcohol) (PVA; $M_{w}, 13000-23000 ; 87-89 \%$ hydrolyzed), and $n$-octadecyl-trimethoxysilane were purchased from Sigma-Aldrich. 2-[Methoxy(polyethyleneoxy)propyl] trimethoxysilane was purchased from Gelest, Inc. These materials were used without further purification. Tetraglycerol condensed ricinoleate (TGCR) was kindly supplied by Sakamoto Yakuhin Kogyo Co. (Japan).

To make the glass capillary devices, cylindrical borosilicate glass tubing (1B100-6, outer diameter and inner diameter are $1.0 \mathrm{~mm}$ and $0.58 \mathrm{~mm}$, respectively) was purchased from World Precision Instruments, and square borosilicate glass tubing (outer dimension and inner dimension are $1.3 \mathrm{~mm}$ and $1.1 \mathrm{~mm}$, respectively) was purchased from Arte Glass Associates Co., Ltd. (Japan).

For the membranes, disk-type hydrophilic SPG membranes with 0.6 $\mathrm{mm}$ thickness and pore sizes of 50,38.4, and $25 \mu \mathrm{m}$ were purchased from SPG Technology Co., Ltd. (Japan), and were used without treatment.

Preparation of the Glass Capillary Device and Generation of W/O/W Emulsion Droplets. The glass capillary device was built on a glass slide, and consisted of a square glass tube and two cylindrical glass tubes, based on the report by Utada et al. ${ }^{17}$ Briefly, the two cylindrical glass tubes were tapered to a diameter of approximately 20 $\mu \mathrm{m}$ with a micropipet puller (P-1000, Sutter Instrument). Their tips were then sanded to make a final diameter ranging from 25 to $300 \mu \mathrm{m}$. $n$-Octadecyl-trimethoxysilane and 2-[methoxy(polyethyleneoxy)propyl]trimethoxysilane were used to modify the surfaces of the cylindrical tubing to be hydrophobic and hydrophilic, respectively. The hydrophobic tube was used as the injection capillary, and the hydrophilic tube was used as the collection capillary. These two tubes were then inserted into the square tubing at both ends, which enabled the alignment of the axes of the injection and collection capillaries.

When $\mathrm{W} / \mathrm{O} / \mathrm{W}$ emulsions were generated, innermost, middle, and outermost fluids were flowed into the device using three microsyringe pumps (CX07100, ISIS Co., Ltd., Japan). The innermost, middle, and outermost fluids used in this study are an aqueous solution containing 7 wt \% glucose, 3 wt \% PVA, and 0.4 or 0.8 wt \% Allura Red, kerosene with $30 \mathrm{wt} \%$ TGCR, and an aqueous solution containing $7 \mathrm{wt} \%$ glucose, 3 wt \% PVA, and $0.25 \%$ SDS, respectively.

Permeation of the W/O/W Emulsion Droplets through SPG Membranes. After collecting the generated $\mathrm{W} / \mathrm{O} / \mathrm{W}$ emulsion droplets generated with a glass capillary device into a syringe, the double emulsions were pumped out through the hydrophilic SPG membrane with pores of $50 \mu \mathrm{m}$ under $1.57 \times 10^{-5}, 1.57 \times 10^{-4}$, or $4.70 \times 10^{-4} \mathrm{~m}^{3} \mathrm{~m}^{-2} \mathrm{~s}^{-1}$ of flux. We removed the oil-in-water $(\mathrm{O} / \mathrm{W})$ emulsion droplets, which had been simultaneously generated during the permeation by using gravity. We then measured the size distribution of the $\mathrm{W} / \mathrm{O} / \mathrm{W}$ emulsion droplets in the permeate with a laser scattering particle size distribution analyzer (LA-950 V2, Horiba Ltd., Japan). The collapsed ratio was defined as an index to discuss how much the double emulsion droplets were collapsed through permeation.

Collapsed ratio $[\%]=($ the number of $\mathrm{W} / \mathrm{O} / \mathrm{W}$ droplets collapsed during permeation through the SPG membrane)/(the number of W/ $\mathrm{O} / \mathrm{W}$ droplets generated with the glass capillary device $) \times 100$.

The number of generated $\mathrm{W} / \mathrm{O} / \mathrm{W}$ droplets was estimated using the total flow rate and the size of the generated $\mathrm{W} / \mathrm{O} / \mathrm{W}$ droplets. The number of $\mathrm{W} / \mathrm{O} / \mathrm{W}$ droplets collapsed during permeation was estimated by the concentration of Allura Red in bulk, measured with a UV-vis spectrophotometer (V-630, JASCO Corporation, Japan).

Preparation of the Membrane-Integrated Glass Capillary Device and Generation of W/O/W Emulsion Droplets. To prepare a membrane-integrated glass capillary device, SPG membranes were sandwiched between two Luer-Stub adapters (Becton, Dickinson and Company), and were connected with a glass capillary device using polyethylene tubing (PE-90, Becton, Dickinson and Company), as shown in Figure 1. The membranes used had pore sizes of 50, 38.4,

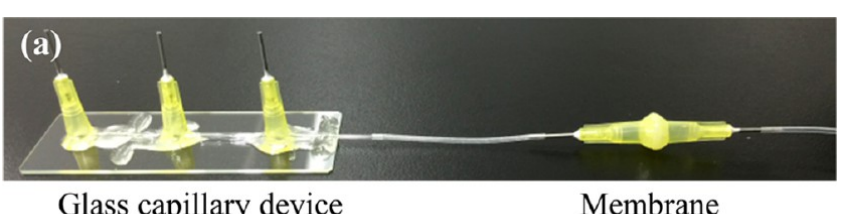

Glass capillary device

Membrane

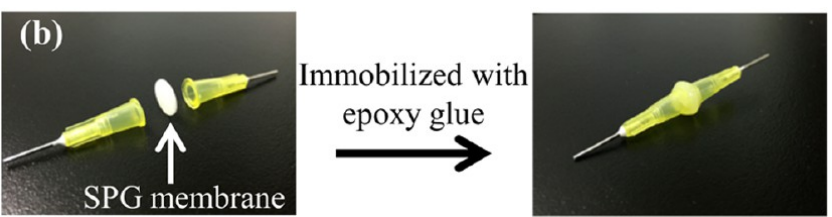

Figure 1. Pictures of (a) the membrane-integrated glass capillary device and (b) the membrane fixation method.

and $25 \mu \mathrm{m}$. In each case, the permeation flux was fixed to be $1.0 \times$ $10^{-4} \mathrm{~m}^{3} \mathrm{~m}^{-2} \mathrm{~s}^{-1}$. The size distribution of the $\mathrm{W} / \mathrm{O} / \mathrm{W}$ emulsion droplets prepared with the membrane-integrated glass capillary device, and the collapsed ratio, were evaluated in the same manner as mentioned in the previous section.

Direct Observation of the Permeation Behavior of Double Emulsion Droplets through the SPG Membrane. A dedicated membrane device, consisting of a slice of SPG membrane and two glass slides, as shown in Figure 2, was fabricated to observe the permeation behavior of the $\mathrm{W} / \mathrm{O} / \mathrm{W}$ emulsion droplets generated with a glass capillary device through an SPG membrane. The SPG membrane sample was cut into a $11.0 \mathrm{~mm}$ long, $4.8 \mathrm{~mm}$ wide, $600-\mu \mathrm{m}$ high cuboid. The SPG membrane and two polyethylene tubes (PE-90, 


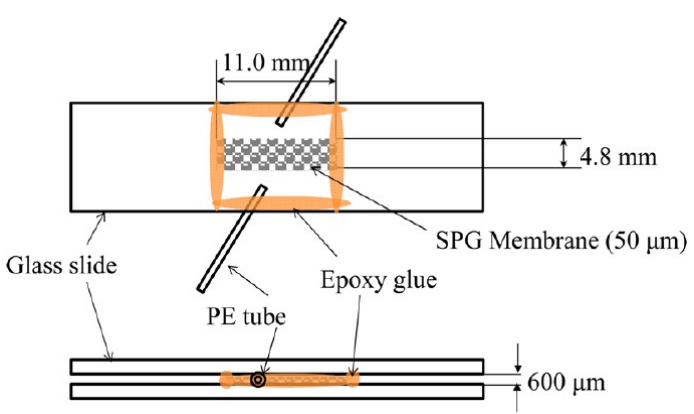

Figure 2. Conceptual illustration of the membrane fixation device for direct observation of the permeation behavior of double emulsion droplets through the SPG membrane.

Becton, Dickinson and Company) were sandwiched by two glass slides and sealed with epoxy resin. This device was directly connected with a glass capillary device, so $\mathrm{W} / \mathrm{O} / \mathrm{W}$ emulsion droplets generated with the glass capillary device were directly supplied to the dedicated membrane device. Permeation behavior through the membrane was observed in situ using a high-speed camera (LRH2510, Digimo Co., Ltd., Japan).

\section{RESULTS AND DISCUSSION}

Permeation of W/O/W Emulsion Droplets through the SPG Membrane under Various Flux. W/O/W emulsion droplets were successfully prepared using the glass capillary device, as shown in Figure $3 a$ and $b$. The flow rates of the innermost $\left(Q_{1}\right)$, the middle $\left(Q_{2}\right)$, and the outermost $\left(Q_{3}\right)$ fluids were 100,500 , and $3000 \mu \mathrm{L} \mathrm{h}^{-1}$, respectively. The average sizes of inner water droplets and outer oil droplets were 88 and $148 \mu \mathrm{m}$, respectively. Hence, the size of the emulsion droplets was larger than the pore size of the membrane. The emulsion droplets produced after permeation through the membrane were smaller in size when compared with those generated with the glass capillary device, as shown in Figure $3 c-e$. This result indicates that the emulsion droplets underwent deformation and division when they permeated the membrane. In addition, it is notable that the shells of the double emulsion droplets after permeation became too thin to be observed by microscope in each flux condition. The size distributions of these $\mathrm{W} / \mathrm{O} / \mathrm{W}$ emulsion droplets after permeation are shown in Figure 4a. The peak diameter decreases slightly with increasing flux. As shown in Figure $4 \mathrm{~b}$, the average size of the $\mathrm{W} / \mathrm{O} / \mathrm{W}$ double emulsion droplet with
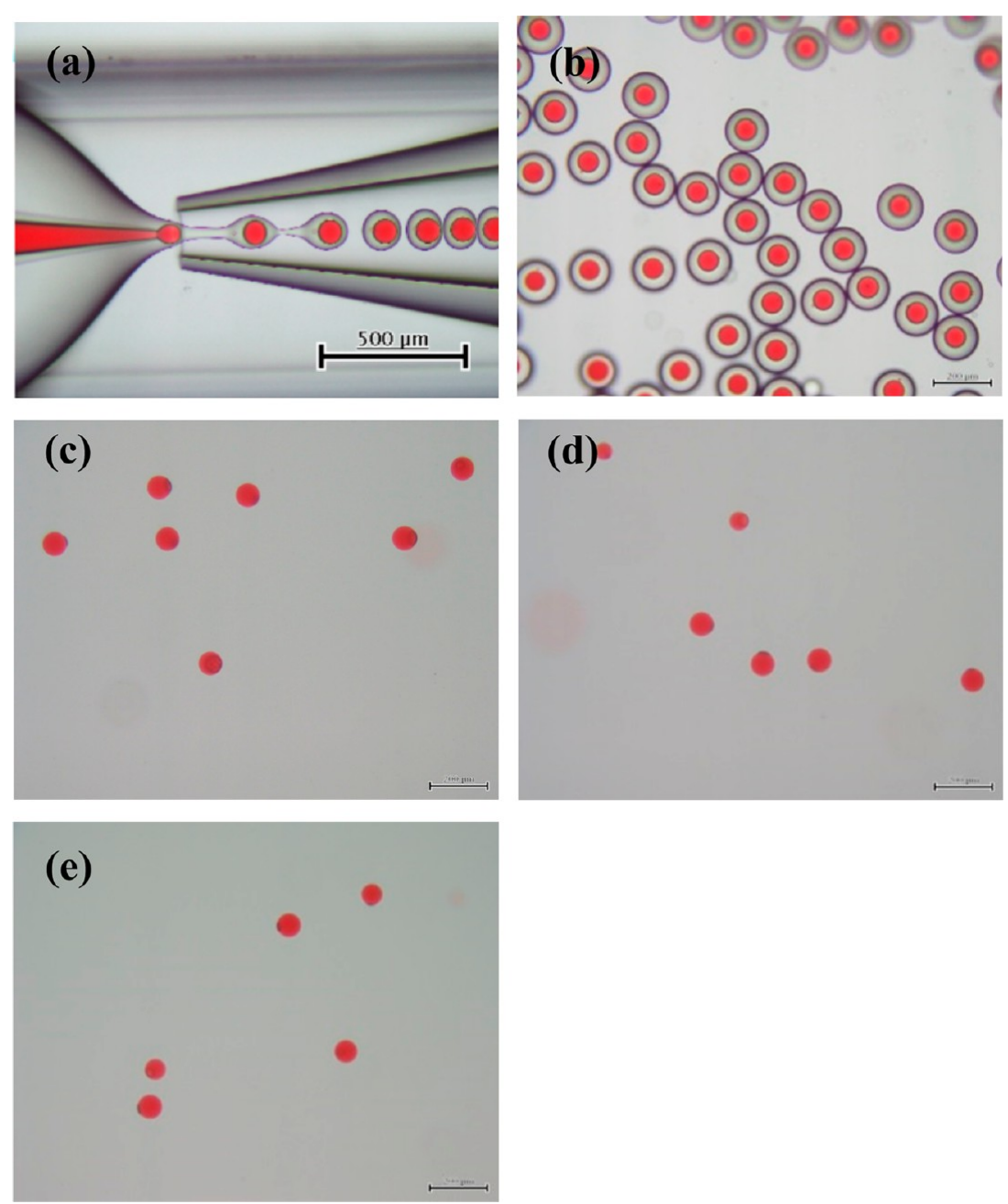

Figure 3. Optical microscope images showing $(\mathrm{a}, \mathrm{b}) \mathrm{W} / \mathrm{O} / \mathrm{W}$ emulsion generated with a glass capillary device $\left(Q_{1}, Q_{2}\right.$, and $Q_{3}$ were 100,500 , and $3000 \mu \mathrm{L} \mathrm{h}^{-1}$, respectively), and $(\mathrm{c}-\mathrm{e}) \mathrm{W} / \mathrm{O} / \mathrm{W}$ emulsion droplets just after the permeation through an SPG membrane with a pore size of $50 \mu \mathrm{m}$ under (c) $1.57 \times 10^{-5}$, (d) $1.57 \times 10^{-4}$, and (e) $4.70 \times 10^{-4} \mathrm{~m}^{3} \mathrm{~m}^{-2} \mathrm{~s}^{-1}$ flux conditions. Scale bar on (a) denotes $500 \mu \mathrm{m}$, and those on (b) $-(\mathrm{e})$ denote $200 \mu \mathrm{m}$. 

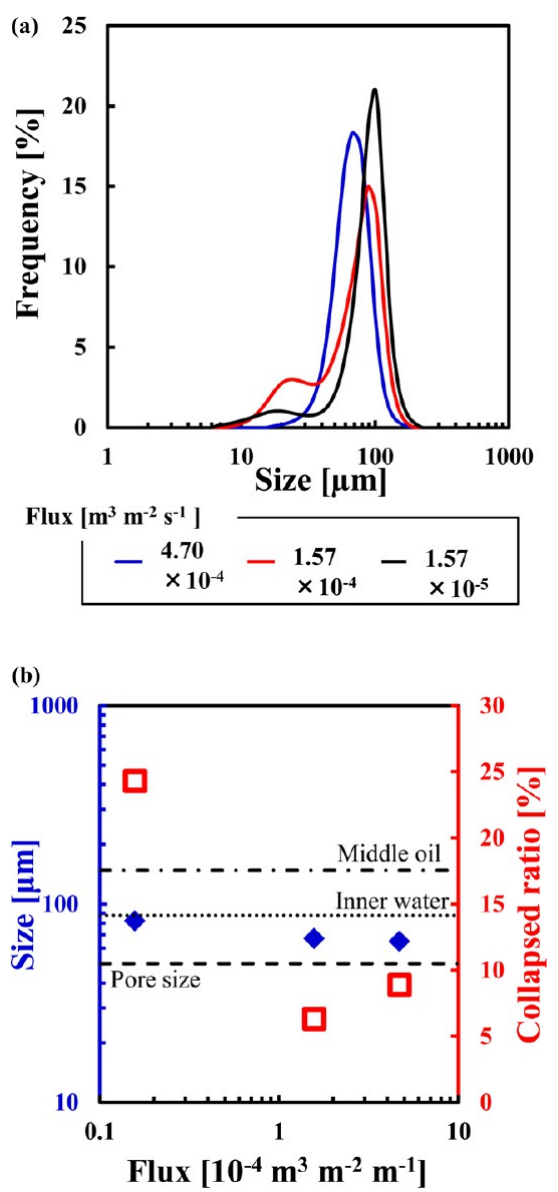

Figure 4. (a) Size distributions of the $\mathrm{W} / \mathrm{O} / \mathrm{W}$ emulsion after permeation with varied flux. (b) Relationships between flux and droplet sizes, and between flux and collapsed ratio.

the lowest flux condition is $82 \mu \mathrm{m}$, which is almost the same size of the inner diameter of the initial $\mathrm{W} / \mathrm{O} / \mathrm{W}$ droplet. The average size gradually decreases with increasing flux, and finally becomes $64 \mu \mathrm{m}$. Under each of the conditions investigated in this study, the size of the double emulsion droplets did not become smaller than the pore size.

The collapsed ratio was $24 \%$ when permeation was carried out at the lowest flux condition, and it decreased to lower than $10 \%$ when the flux was higher. The exact reason for this trend is not clear at this stage, but we propose that a lower flux is unable to sweep excess oil away from the membrane and pore surfaces, inducing the unfavorable collapse of double emulsion droplets.

Generation of W/O/W Emulsion Droplets with an Integrated Device: The Effect of Pore Size. Figure 5a shows the size distributions of the $\mathrm{W} / \mathrm{O} / \mathrm{W}$ emulsion droplets, prepared with the integrated devices using membranes with pore sizes of 50, 38.4, and $25 \mu \mathrm{m}$. The size of the emulsion droplets prepared with an integrated device became smaller when using a membrane with a smaller pore size, which was as small as $48 \mu \mathrm{m}$ when the integrated device including a membrane with a pore size of $25 \mu \mathrm{m}$ was employed. Thus, membrane pore size affects the double emulsion droplet size. The relationships between the pore size and the double emulsion droplet size, and between the pore size and the collapsed ratio are shown in Figure $5 b$. The flux condition was fixed to be $1.0 \times 10^{-4} \mathrm{~m}^{3} \mathrm{~m}^{-2} \mathrm{~s}^{-1}$ in each case, and the size of the emulsion droplets generated at the glass capillary device was
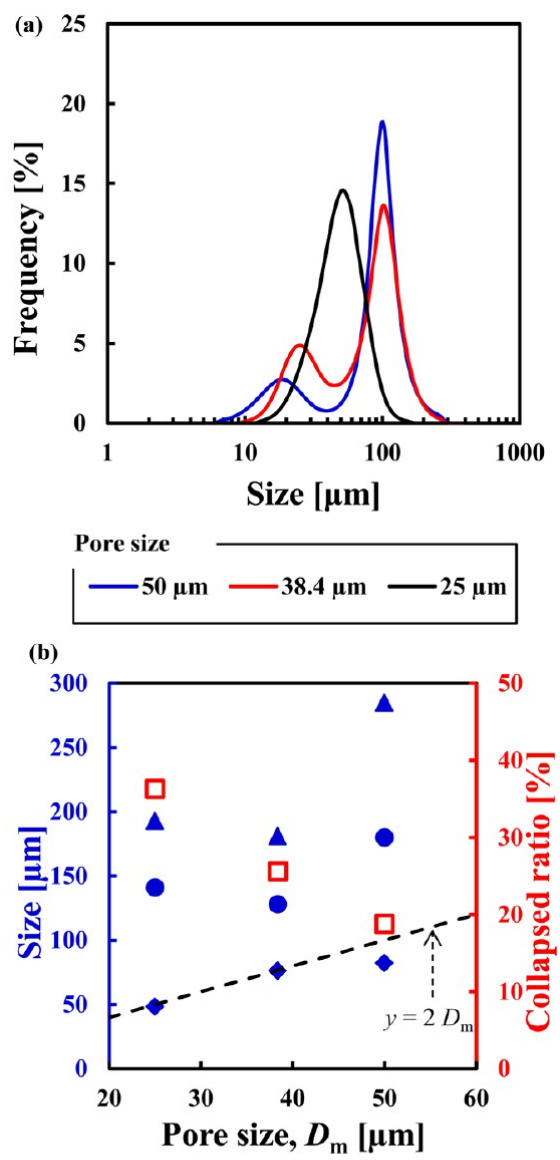

- Diameter of inner droplet before permeation $\Delta$ Diameter of middle droplet before permeation - Size of $\mathrm{W} / \mathrm{O} / \mathrm{W}$ droplet after permeation $\square$ Collapsed ratio

Figure 5. (a) Size distributions of the $\mathrm{W} / \mathrm{O} / \mathrm{W}$ emulsion prepared using the integrated device with SPG membranes having different pore sizes. (b) Relationships between flux and droplet sizes, and between flux and collapsed ratio.

much larger than the pore sizes (shown with closed triangle and circle data points). Hence, this test shows the effect of pore size, and that the size of the double emulsion droplets can be controlled by varying membrane pore size. As shown in Figure $5 b$, the size of the emulsion droplets with an integrated device was approximately double the pore size of the SPG membranes. This is because the flux condition was not high. The collapsed ratio became higher as the pore size of the SPG membrane decreased. The ratio of the membrane pore size to the size of the double emulsion droplets before permeation is important. When the ratio is small, the double emulsion droplets are deformed to pass through the membrane and, consequently, the probability of double emulsion droplet collapse increases.

Repeated Permeation of W/O/W Emulsion Droplets through the SPG Membrane. Figure 6 shows the size distribution of the $\mathrm{W} / \mathrm{O} / \mathrm{W}$ emulsion droplets generated with the integrated device. This was done by generating the double emulsion droplets at the glass capillary device followed by their permeation through an SPG membrane with $50 \mu \mathrm{m}$ pores. These double emulsion droplets were forced through the same SPG membrane two more times. These size distributions are also shown in Figure 6. For each passing, the flux was set at 1.9 $\times 10^{-4} \mathrm{~m}^{3} \mathrm{~m}^{-2} \mathrm{~s}^{-1}$. The average size of the emulsion droplets generated with the integrated device was $83 \mu \mathrm{m}$, which is less 


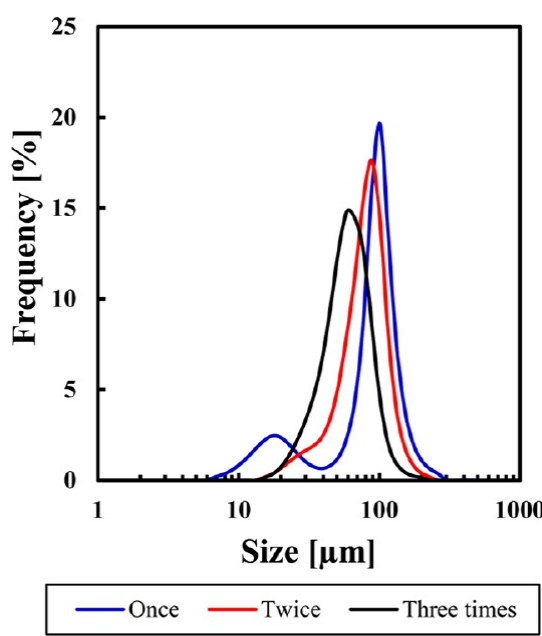

Figure 6. Relationship between the number of passages through the membrane and the size distribution of $\mathrm{W} / \mathrm{O} / \mathrm{W}$ emulsion droplets.

than double the pore size. The average size decreased with the number of passages through the membrane; it was $76 \mu \mathrm{m}$ after the second permeation, and $56 \mu \mathrm{m}$ after the third. This was closer to the pore size of the membrane. The reason why the size did not become smaller than the pore size was because such small double emulsion droplets are able to undergo permeation without any deformation or division. It was demonstrated that the repeated passing of the $\mathrm{W} / \mathrm{O} / \mathrm{W}$ emulsion droplets through the membrane resulted in a decrease of their average size. In fact, there have been some reports on repeated permeation of single emulsion droplets. Ribeiro et al. $^{28}$ repeatedly passed a preprepared $\mathrm{O} / \mathrm{W}$ emulsion through a hydrophilic membrane and reported that a decrease of the droplet size was observed with increasing passage number. Furthermore, there is a report on the repeated passage of liposomes, which are also deformable, through SPG membranes by Hwang et al. ${ }^{29}$ They first prepared primary liposomes by a film-hydration method, and extruded them through SPG membranes. This is similar to an extrusion method for obtaining size-controlled and monodispersed liposomes, but to the best of our knowledge, this is the first example using SPG membranes. These authors observed the same tendency, that is, the liposome size gradually decreased with increasing passage
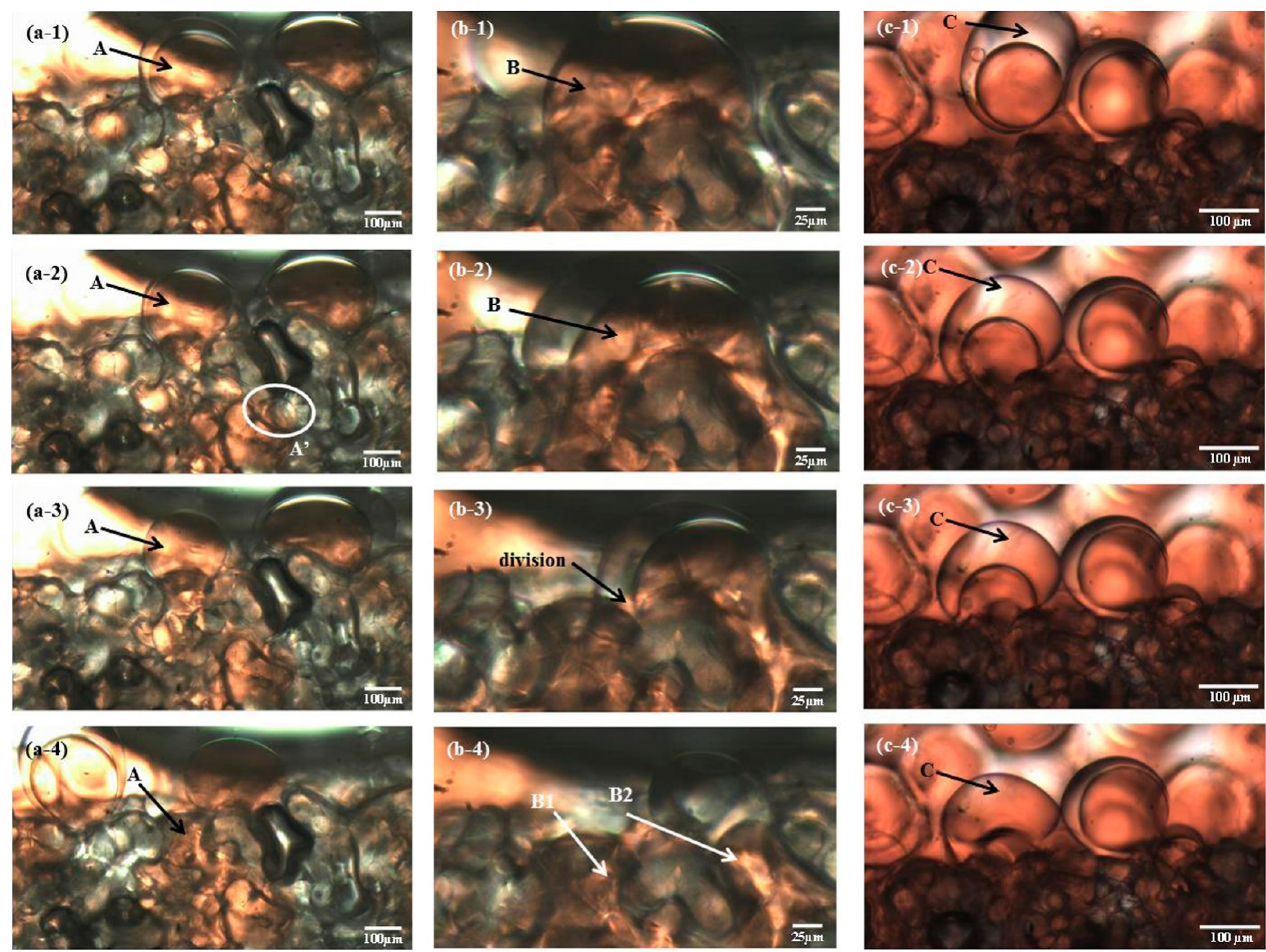

Figure 7. In situ observation of the permeation properties of W/O/W emulsion droplets through the SPG membrane with pores of $50 \mu \mathrm{m}$. (a) Stripping of the middle phase ( (a-1) $0 \mathrm{~s},(\mathrm{a}-2) 0.168 \mathrm{~s}$, (a-3) $0.550 \mathrm{~s},(\mathrm{a}-4) 2.250 \mathrm{~s})$, (b) division of double emulsion droplets to generate two or more droplets with smaller sizes ((b-1) $0 \mathrm{~s},(\mathrm{~b}-2) 0.038 \mathrm{~s}$, (b-3) $0.119 \mathrm{~s},(\mathrm{~b}-4) 0.210 \mathrm{~s})$, and (c) collapse of double emulsion droplets ((c-1) $0 \mathrm{~s},(\mathrm{c}-2)$ $0.064 \mathrm{~s},(\mathrm{c}-3) 0.065 \mathrm{~s},(\mathrm{c}-4) 0.096 \mathrm{~s})$. 
(a)

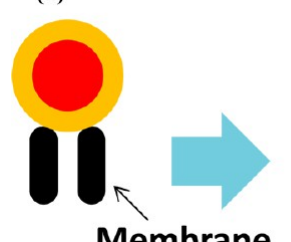

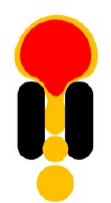
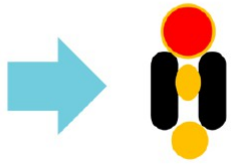

(b)

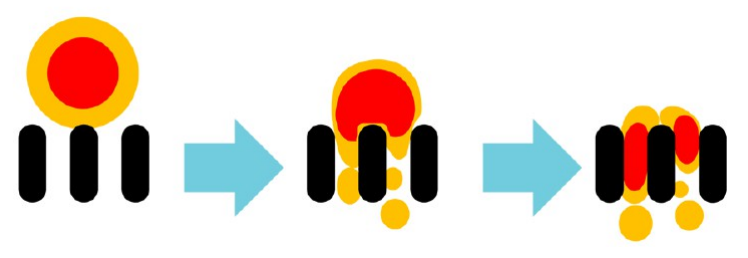

Figure 8. Conceptual illustrations of (a) the stripping of the middle phase and (b) the division of double emulsion droplets to generate two or more components with smaller sizes. These phenomena result in the generation of smaller-sized $\mathrm{W} / \mathrm{O} / \mathrm{W}$ emulsion droplets with thin shells.

number, and the size of the obtained liposomes decreased with decreasing the pore size of the membrane used.

Direct Observation of the Permeation Behavior of Double Emulsion Droplets through the SPG Membrane. We noted three important phenomena by directly observing the permeation behavior of $\mathrm{W} / \mathrm{O} / \mathrm{W}$ emulsion droplets with a high-speed camera. The first phenomenon was the stripping of the middle phase. Some double emulsion droplets did not proceed smoothly through the membrane pores but remained at the membrane surface, and in this instance, only the middle oil phase was stripped, resulting in the generation of single $\mathrm{O} /$ $\mathrm{W}$ emulsion droplets, as shown in Figure 7a. Double emulsion droplet A remained at the membrane surface, and smaller $\mathrm{O} / \mathrm{W}$ emulsion droplets, such as emulsion droplet $\mathrm{A}^{\prime}$, were generated from the stripped oil layer. This most likely arises from the shear force acting on the double emulsion droplets, in particular on the shell layer, by the flow of the outermost fluid into the pores. This phenomenon made the shell of the double emulsion droplets thinner. The second phenomenon is the division of double emulsion droplets to generate two or more smaller components, as shown in Figure $7 \mathrm{~b}$. The double emulsion droplet B divided into double emulsion droplet B1 and B2. The double emulsion droplets faced two or more pores on the membrane surface at the same time, and the middle oil phase started deforming to divide into two or more droplets. The inner water droplet accordingly proceeded to deform into two or more components, which then, with the division process finally complete, flowed into different pores. This resulted in the generation of smaller-sized $\mathrm{W} / \mathrm{O} / \mathrm{W}$ emulsion droplets. The last phenomenon is the collapse of double emulsion droplets. It would have been preferable to avoid this phenomenon, but it did occur, as shown in Figure 7c. In this case, the inner water droplet and the middle oil shell collapsed almost at the same time, and the middle oil phase formed a single $\mathrm{O} / \mathrm{W}$ emulsion droplet with the flow of the outermost water fluid.

These observations were only carried out at the membrane surface for the retentate, as it was difficult to obtain clearer pictures, and it was impossible to observe the inner membrane structure. However, we were able to observe these three phenomena, which should be repeatedly occurring inside the membrane pores, in particular at the junctions where two or more pores connect or where one pore branches to two or more. As shown in Figure 8, the stripping phenomenon of the middle phase results in making the oil shell thinner, and the division phenomenon results in making the double emulsion droplets smaller. When the size of the droplet becomes equivalent to the pore size of the membrane, the droplet easily passes through the membrane without deformation or division. As a result, we can obtain smaller-sized double emulsion droplets with thin shells after permeating through SPG membranes. Additionally, the collapsing phenomenon may occur during permeation; however, at this stage, it cannot be avoided completely. This may be an issue for further research.

\section{CONCLUSION}

We investigated the permeation properties of $\mathrm{W} / \mathrm{O} / \mathrm{W}$ emulsion droplets, which were generated with glass capillary devices through SPG membranes. We then developed membrane integrated glass capillary devices to prepare smallsized $\mathrm{W} / \mathrm{O} / \mathrm{W}$ emulsion droplets. Permeation flux through the SPG membranes and SPG membrane pore size greatly affected the resultant double emulsion droplets. The double emulsion droplets after the permeation became smaller in size with a thin shell. When the permeation flux was increased and the pore size of the SPG membrane used was decreased, the size of the double emulsion droplets became smaller. When the flux was small $\left(\sim 1 \times 10^{-4} \mathrm{~m}^{3} \mathrm{~m}^{-2} \mathrm{~s}^{-1}\right)$, the size of the double emulsion droplets was approximately twice as large as the pore size, and it became comparative to the pore size when the flux was larger and when the number of passages through the SPG membrane was higher. In this study, we successfully prepared $\mathrm{W} / \mathrm{O} / \mathrm{W}$ emulsion droplets whose sizes were as small as $48 \mu \mathrm{m}$. The in situ observation of the permeation behavior of $\mathrm{W} / \mathrm{O} / \mathrm{W}$ emulsion droplets through the SPG membrane demonstrated three important phenomena: (1) the stripping of the middle phase of the double emulsion droplets, (2) the division of double emulsion droplets to generate two or more components, which were smaller than the original droplet, and (3) the collapse of double emulsion droplets. W/O/W emulsion droplets repeatedly underwent these phenomena during permeation through the SPG membrane. The stripping phenomenon of the middle phase resulted in making the oil shell thinner with the generation of $\mathrm{O} / \mathrm{W}$ emulsion droplets. The division phenomenon resulted in making the double emulsion droplets smaller. Thus, we can conclude that we have successfully developed a membrane-integrated glass capillary device which enables the generation of $\mathrm{W} / \mathrm{O} / \mathrm{W}$ emulsion droplets less than $100 \mu \mathrm{m}$ in size.

\section{ASSOCIATED CONTENT}

\section{S Supporting Information}

Three videos showing the three phenomena as shown in Figure 7. The Supporting Information is available free of charge on the ACS Publications website at DOI: 10.1021/acs.langmuir.5b01514.

\section{AUTHOR INFORMATION}

\section{Corresponding Author}

*Tel: +81-42-628-4584. Fax: +81-42-628-4542. E-mail: akamatsu@cc.kogakuin.ac.jp.

\section{Notes}

The authors declare no competing financial interest. 


\section{ACKNOWLEDGMENTS}

TGCR was kindly supplied by Sakamoto Yakuhin Kogyo Co., Japan. The work at Harvard was supported by the NSF (DMR1310266) and by the Harvard MRSEC (DMR-1420570).

\section{REFERENCES}

(1) McClements, D. J. Advances in fabrication of emulsions with enhanced functionality using structural design principles. Curr. Opin. Colloid Interface Sci. 2012, 17, 235-245.

(2) Muschiolik, G. Multiple emulsions for food use. Curr. Opin. Colloid Interface Sci. 2007, 12, 213-220.

(3) Kim, S.-H.; Kim, J. W.; Cho, J.-C.; Weitz, D. A. Double-emulsion drops with ultra-thin shells for capsule templates. Lab Chip 2011, 11, 3162-3166.

(4) Chen, P. W.; Erb, R. M.; Studart, A. R. Designer polymer-based microcapsules made using microfluidics. Langmuir 2012, 28, 144-152.

(5) Wang, T.; Deng, Y.; Geng, Y.; Gao, Z.; Zou, J.; Wang, Z. Preparation of submicron unilamellar liposomes by freeze-drying double emulsions. Biochim. Biophys. Acta, Biomembr. 2006, 1758, 222231.

(6) Arriaga, L. R.; Datta, S. S.; Kim, S.-H.; Amstad, E.; Kodger, T. E.; Monroy, F.; Weitz, D. A. Ultrathin shell double emulsion template giant unilamellar lipid vesicles with controlled microdomain formation. Small 2014, 10, 950-956.

(7) Funakoshi, K.; Suzuki, H.; Takeuchi, S. Formation of giant lipid vesiclelike compartment from a planar lipid membrane by a pulsed jet flow. J. Am. Chem. Soc. 2007, 129, 12608-12609.

(8) Sander, J. S.; Studart, A. R. Monodisperse functional colloidsomes with tailored nanoparticle shells. Langmuir 2011, 27, 3301-3307.

(9) Lee, D.; Weitz, D. A. Double emulsion-templated nanoparticle colloidosomes with selective permeatbility. Adv. Mater. 2008, 20, 3498-3503.

(10) Perro, A.; Nicolet, C.; Angly, J.; Lecommandoux, S.; Le Meins, J.-F; Colin, A. Mastering a double emulsion in a simple co-flow microfluidic to generate complex polymersomes. Langmuir 2011, 27, 9034-9042.

(11) Kamat, N. P.; Lee, M. H.; Lee, D.; Hammer, D. A. Micropipette aspiration of double emulsion-templated polymersomes. Soft Matter 2011, 7, 9863-9866.

(12) Joanicot, M.; Ajdari, A. Droplet control for microfluidics. Science 2005, 309, 887-888.

(13) Okushima, S.; Nishisako, T.; Torii, T.; Higuchi, T. Controlled production of monodipserse double emulsions by two-step droplet breakup in microfluidic devices. Langmuir 2004, 20, 9905-9908.

(14) Vladisavljević, G. T.; Shimuzu, M.; Nakashima, T. Preparation of monodisperse multiple emulsions at high production rates by multistage premix membrane emulsification. J. Membr. Sci. 2004, 244, 97106.

(15) Nishisako, T.; Okushima, S.; Torii, T. Controlled formulation of monodisperse double emulsions in a multiple-phase microfluidic system. Soft Matter 2005, 1, 23-27.

(16) Chu, L.-Y.; Utada, A. S.; Shah, R. K.; Kim, J.-W.; Weitz, D. A. Controllable monodisperse multiple emulsions. Angew. Chem., Int. Ed. 2007, 46, 8970-8974.

(17) Utada, S.; Lorenceau, E.; Link, D. R.; Kaplan, P. D.; Stone, H. A.; Weitz, D. A. Monodisperse double emulsions generated from a microcapillary device. Science 2005, 308, 537-541.

(18) Adams, L. L. A.; Kodger, T. E.; Kim, S.-H.; Shum, H. C.; Franke, T.; Weitz, D. A. Single step emulsification for the generation of multicomponent double emulsions. Soft Matter 2012, 8, 10719-10724.

(19) Kim, S.-H.; Weitz, D. A. One-step emulsification of multiple concentric shells with capillary microfluidic device. Angew. Chem., Int. Ed. 2011, 50, 8731-8734.

(20) Nakashima, T.; Shimizu, M.; Kukizaki, M. Membrane emulsification by microporous glass. Key Eng. Mater. 1991, 61/62, $513-516$.
(21) Nakashima, T.; Shimizu, M.; Kukizaki, M. Particle control of emulsion by membrane emulsification and its applications. Adv. Drug Delivery Rev. 2000, 45, 47-56.

(22) Suzuki, K.; Shuto, I.; Hagura, Y. Characteristics of the membrane emulsification method combined with preliminary emulsification for preparing corn oil-in-water emulsions. Food Sci. Technol. Int. 1996, 2, 43-47.

(23) Suzuki, K.; Fujiki, I.; Hagura, Y. Preparation of corn oil/water and water/corn oil emulsions using PTFE membranes. Food Sci. Technol. Int. 1998, 4, 164-167.

(24) Lv, P.-P.; Wei, W.; Gong, F.-L.; Zhang, Y.-L.; Zhao, H.-Y.; Lei, J.-D.; Wang, L.-Y.; Ma, G.-H. Preparation of uniformly sized chitosan nanospheres by a premix membrane emulsification technique. Ind. Eng. Chem. Res. 2009, 48, 8819-8828.

(25) Kukizaki, M. Preparation of solid lipid microcapsules via solidin-oil-in-water despersions by premix membrane emulsification. Chem. Eng. J. 2009, 151, 387-396.

(26) Ramakrishnan, S.; Ferrando, M.; Aceña-Muñoz, L.; De LamoCastellví, S.; Güell, C. Fish oil microcapsules from O/W emulsions produced by premix membrane emulsification. Food Bioprocess Technol. 2013, 6, 3088-3101.

(27) Kukizaki, M.; Goto, M. Demulsification of water-in-oil emulsions by permeation through Shirasu-porous-glass (SPG) membranes. J. Membr. Sci. 2008, 322, 196-203.

(28) Ribeiro, H. S.; Rico, L. G.; Badolato, G. G.; Schubert, H. Production of $\mathrm{O} / \mathrm{W}$ emulsions containing astaxanthin by repeated premix membrane emulsification. J. Food Sci. 2005, 70, E117-E123.

(29) Hwang, T.; Park, T.-J.; Koh, W.-G.; Cheong, I. W.; Choi, S.-W.; Kim, J. H. Fabrication of nano-scale liposomes containing doxorubicin using Shirasu porous glass membrane. Colloids Surf., A 2011, 392, $250-255$. 